\title{
Comprehensive Knowledge Assessment for Athletic Trainers: Part I
}

\author{
Lindsey E. Eberman \\ Indiana State University, leberman@indstate.edu \\ Jessica R. Edler \\ Grand View University, jedler@grandview.edu \\ Kenneth E. Games \\ Indiana State University, kenneth.games@indstate.edu
}

Follow this and additional works at: https://nsuworks.nova.edu/ijahsp

Part of the Medical Education Commons, and the Sports Sciences Commons

\section{Recommended Citation}

Eberman LE, Edler JR, Games KE. Comprehensive Knowledge Assessment for Athletic Trainers: Part I. The Internet Journal of Allied Health Sciences and Practice. 2019 Jan 01;17(4), Article 13.

This Manuscript is brought to you for free and open access by the College of Health Care Sciences at NSUWorks. It has been accepted for inclusion in Internet Journal of Allied Health Sciences and Practice by an authorized editor of NSUWorks. For more information, please contact nsuworks@nova.edu. 


\title{
Comprehensive Knowledge Assessment for Athletic Trainers: Part I
}

\begin{abstract}
Purpose: Continuing education (CE) is intended to help clinicians maintain competence, develop and advance knowledge and skills, and enhance knowledge, skills, and abilities beyond the levels required for entry-level practice. Based on previous literature, the current mode of CE in athletic training does not appear to be helping clinicians maintain competence. The purpose of this research was to validate a comprehensive assessment based on the Role Delineation Study/Practice Analysis ( $6^{\text {th }}$ ed.) through item analysis and estimates of reliability to be used to assess athletic trainers' actual knowledge. Method: We conducted an instrumentation validation study using Qualtrics ${ }^{\circledR}$ web-based platform. Athletic trainers $(n=191$; age $=31.5 \pm 8.1 \mathrm{yrs}$; years of experience $=8.9 \pm 11.1 \mathrm{yrs})$ in good standing with the NATA and BOC completed both administrations of the assessment. Six experts developed 220 multiple-choice items for inclusion with broad application across the five domains of clinical practice (Injury/lllness and Wellness Protection [49 items], Clinical Evaluation and Diagnosis [63 items], Immediate and Emergency Care [29 items], Treatment and Rehabilitation [29 items], and Organizational and Professional Health and Wellbeing [50 items]). A random sample of NATA members were recruited via email, received weekly reminders, and then after four weeks, they completed a second administration of the assessment. We evaluated the assessment tool for item difficulty, item discrimination, internal consistency, item total statistics, and testretest reliability. Results: We eliminated 42 items from the tool created by the experts that were too difficult (0.90). We eliminated 50 additional items due to point-biserial correlations between item performance and total domain score performance below 0.20 . We identified additional weaknesses in 57 items through intraclass correlation coefficients (ICCConclusions: We developed a valid and reliable assessment tool to measure athletic trainers' actual knowledge. Future research should utilize a validated assessment of actual knowledge to guide continuing education activities.
\end{abstract}

\section{Author Bio(s)}

Lindsey E. Eberman is a Professor and the Program Director of the Post-Professional Doctor of Athletic Training program in the College of Health and Human Services at Indiana State University in Terre Haute, IN. She is also a licensed athletic trainer in the state of Indiana.

Jessica R. Edler is an Assistant Professor and the Clinical Education Coordinator of the Professional Masters Athletic Training program at Grand View University in Des Moines, IA. She is also a licensed athletic trainer in the state of lowa.

Kenneth E. Games is an Associate Professor and the Director of Clinical Education of the Doctor of Athletic Training program in the College of Health and Human Services at Indiana State University in Terre Haute, IN. He is also a licensed athletic trainer in the state of Indiana. 


\title{
IIAAHSP
}

\section{The Internet Journal of Allied Health Sciences and Practice}

Dedicated to allied health professional practice and education

Vol. 17 No. 4 ISSN 1540-580X

\section{Comprehensive Knowledge Assessment for Athletic Trainers: Part 1}

\author{
Lindsey E. Eberman ${ }^{1}$ \\ Jessica R. Edler ${ }^{2}$ \\ Kenneth E. Games ${ }^{1}$ \\ 1. Indiana State University \\ 2. Grand View University \\ United States
}

\begin{abstract}
Purpose: Continuing education (CE) is intended to help clinicians maintain competence, develop and advance knowledge and skills, and enhance knowledge, skills, and abilities beyond the levels required for entry-level practice. Based on previous literature, the current mode of $\mathrm{CE}$ in athletic training does not appear to be helping clinicians maintain competence. The purpose of this research was to validate a comprehensive assessment based on the Role Delineation Study/Practice Analysis (6 ${ }^{\text {th }}$ ed.) through item analysis and estimates of reliability to be used to assess athletic trainers' actual knowledge. Method: We conducted an instrumentation validation study using Qualtrics ${ }^{\circledR}$ web-based platform. Athletic trainers $(n=191$; age $=31.5 \pm 8.1 \mathrm{yrs}$; years of experience $=8.9 \pm 11$. $1 \mathrm{yrs}$ ) in good standing with the NATA and BOC completed both administrations of the assessment. Six experts developed 220 multiple-choice items for inclusion with broad application across the five domains of clinical practice (Injury/llness and Wellness Protection [49 items], Clinical Evaluation and Diagnosis [63 items], Immediate and Emergency Care [29 items], Treatment and Rehabilitation [29 items], and Organizational and Professional Health and Wellbeing [50 items]). A random sample of NATA members were recruited via email, received weekly reminders, and then after four weeks, they completed a second administration of the assessment. We evaluated the assessment tool for item difficulty, item discrimination, internal consistency, item total statistics, and test-retest reliability. Results: We eliminated 42 items from the tool created by the experts that were too difficult $(<0.20)$ or too easy $(>0.90)$. We eliminated 50 additional items due to point-biserial correlations between item performance and total domain score performance below 0.20 . We identified additional weaknesses in 57 items through intraclass correlation coefficients (ICC $<0.5)$. The remaining 71 items demonstrated high internal consistency (Cronbach's $a=0.843$ ) and each domain demonstrated good or excellent reliability between administrations (ICC=0.617-0.820). Conclusions: We developed a valid and reliable assessment tool to measure athletic trainers' actual knowledge. Future research should utilize a validated assessment of actual knowledge to guide continuing education activities.
\end{abstract}

Keywords: continuing education, role delineation, educational competencies, actual knowledge 


\section{INTRODUCTION}

Continuing education (CE) is the primary mechanism for health care professionals to retain their licenses or certifications and to ensure that they maintain competence while developing knowledge and skills consistent with current standards of practice. ${ }^{1}$ Continuing education is any and all learning and knowledge acquired after formal training completion. ${ }^{2}$ Continuing education is intended to promote continued competence, develop current knowledge and skills, and enhance professional skills and judgment beyond the levels required for entry-level practice. ${ }^{1}$ Continued learning and maintaining competence as a healthcare provider is a characteristic of professionalism ${ }^{1}$ and helps to protect the public's safety. ${ }^{3}$ Often $\mathrm{CE}$ is motivated by the learner's perception of his or her own knowledge, by personal preference, or by a current clinical problem, and learners are deterred from CE because of time, cost, and course relevance. ${ }^{4}$ Additionally, practitioners seem incapable of truly recognizing gaps in their own clinical practice (often with notable deficits in actual knowledge), both in athletic training and in other professions. ${ }^{5-14}$ As such, practitioners may not select or acquire appropriate CE to maintain competence or resolve knowledge deficits that may result in knowledge and skill gaps related to current best practices. Although this has not been measured systematically in athletic training, cases like those of Jordan McNair (University of Maryland), Ereck Plancher (University of Central Florida), and data from other healthcare professions show that inadequate knowledge and skill decay can negatively affect patients, which could have life altering results. ${ }^{15-18}$

In athletic training, students are trained using educational competencies, which only recently came under the direction of the Commission on Accreditation of Athletic Training Education (CAATE) in the development of the curricular content standards (previously developed by the Professional Education Committee of the National Athletic Trainers' Association [NATA]). ${ }^{19}$ Practicing clinicians help to define the practice of the profession by engaging in the Role Delineation Study/Practice Analysis (6 ${ }^{\text {th }}$ ed.) facilitated by the Board of Certification (BOC or Board), creating the blueprint for examining entry-level knowledge for initial Board certification. ${ }^{20}$ Initial Board Certification Examination includes all domains of practice to ensure competence across all practice areas (Injury/lllness and Wellness Protection [Domain 1], Clinical Evaluation and Diagnosis [Domain 2], Immediate and Emergency Care [Domain 3], Treatment and Rehabilitation [Domain 4], and Organizational and Professional Health and Wellbeing [Domain 5]). ${ }^{20}$ According to the BOC, to maintain certification one must engage in a minimum number of $\mathrm{CE}$ units with the goal that these CE units "promote continued competence" in the aforementioned domains. ${ }^{1}$ Presumably, that means, athletic trainers should maintain a level of competence commensurate with that possessed when they became Board certified. Yet CE is also intended, as is stated by the BOC, to develop current knowledge and skills like those that are being taught in educational programs (educational competencies), suggesting that $\mathrm{CE}$ is also supposed to push practitioners to develop their knowledge and skills to current practice standards. ${ }^{1}$ According to these stated intentions, CE should help practitioners maintain and develop current knowledge and skills.

Continuing education sessions are effective, at least in positively affecting patients, but practitioners may not be capable of recognizing where their knowledge needs exist. ${ }^{5-14,21-28}$ This suggests an alternative approach to maintaining competence may be needed to ensure patient safety and high quality healthcare in athletic training and other healthcare professions. Alternative approaches to $\mathrm{CE}$ have been explored in several health professions, but most notably in emergency and family medicine specialties where maintenance of competence is developed through four tenets: 1) standards in professional standing, 2) lifelong learning and self-assessment, 3) cognitive expertise, and 4) assessment of practice performance. ${ }^{29-34}$ We hypothesize that external feedback using a comprehensive examination to identify domain-specific knowledge deficits may be helpful in guiding practitioners to CE that will resolve knowledge deficits. Physician assistant practice, emergency medicine, and family medicine have used recertifying exams to ensure maintenance of competence. ${ }^{29-33}$ However, a knowledge assessment, like the one proposed in this study, not a recertifying exam, could be more formative and used to help athletic trainers identify knowledge gaps; subsequently, these individuals could then select CE that meets their knowledge needs. This theory has been preliminarily studied, whereby external feedback suggesting poor performance resulted in a stated desire to seek CE. ${ }^{5}$ In this study, we focused on the development and validation of a comprehensive, competency-based examination that could be used in future research and practice to maintain competency in athletic trainers. The specific aim of this study is to validate a comprehensive knowledge assessment based on the Crosswalk Analysis ${ }^{35}$ that bridges the Role Delineation Study/Practice Analysis ( $6^{\text {th }}$ ed.) and educational competencies through item analysis and estimates of reliability. ${ }^{19,20}$

\section{METHODS}

\section{Design}

We developed a comprehensive knowledge assessment and then conducted an instrument validation study.

\section{Participants}

One-hundred and ninety-one athletic trainers (age $=31.5 \pm 8.1 \mathrm{yrs}$; years of experience $=8.9 \pm 11$.1yrs) in good standing with the NATA and BOC completed both administrations of the assessment (Table 1). Only those who completed greater than $60 \%$ of 
the entire assessment were included in analysis (this is the score cut-off used by the BOC Certification Examination). All participants were informed about the study and provided consent to participate. The study was deemed exempt research by the Indiana State University Institutional Review Board.

Table 1. Participant Demographics $(N=191)$

\begin{tabular}{lr} 
Characteristic & Frequency (\%) \\
\hline Sex & \\
Male & $53(27.7)$ \\
Female & $137(71.7)$ \\
Genderqueer & $1(0.5)$ \\
Current Clinical Setting & \\
College/University & $64(33.5)$ \\
Secondary/lntermediate & $66(34.6)$ \\
Clinic/Hospital & $34(17.8)$ \\
Professional sports & $2(1.0)$ \\
Performing arts & $0(0.0)$ \\
Public Safety & $0(0.0)$ \\
Military & $4(2.1)$ \\
Occupational health & $3(1.6)$ \\
Other & $18(9.4)$ \\
Highest Degree Earned & \\
Bachelor's (BA, BS, etc) & $47(24.6)$ \\
Master's (MA, MS, etc) & $136(71.2)$ \\
Clinical Doctorate (DAT, DHS, DHSc, etc) & $4(2.1)$ \\
Academic Doctorate (PhD, EdD, etc) & $4(2.1)$ \\
\hline
\end{tabular}

\section{Instrumentation}

We developed our assessment tool using a process similar to the cognitive assessments used in emergency and family medicine specialties. ${ }^{29-31}$ To develop the tool, we identified seven item writers from a pool of expert clinicians, educators, and researchers who were either tasked with developing the $5^{\text {th }}$ Edition of the Educational Competencies $(n=6)$ or who were referred by a member of the pool of experts $(n=1)$. The pool of experts developed 220 multiple-choice items, referenced from the BOC Exam Reference List and NATA Position Statements, for inclusion with broad application across the five domains of clinical practice (Injury/lllness and Wellness Protection [49 items], Clinical Evaluation and Diagnosis [63 items], Immediate and Emergency Care [29 items], Treatment and Rehabilitation [29 items], and Organizational and Professional Health and Wellbeing [50 items]). ${ }^{36,37}$ We then used the Crosswalk Analysis to translate items from the educational competency areas to their respective domains to align with the Role Delineation Study/Practice Analysis. ${ }^{34,35}$ Items were entered into the Qualtrics ${ }^{\circledR}$ web-based platform, and randomization was used for item order and response order.

\section{Procedures}

Participants were solicited from a random sample of NATA members by email. We contacted individuals via email to identify interested participants, sent weekly reminders, and four weeks after the initial administration, $89 \%(n=177)$ of the participants completed a second administration of the assessment.

\section{Statistical Analysis}

We completed an industry standard, step by step analysis of the data in its entirety, more multifaceted than the item analysis conducted by the BOC. $38-40$ This process included individual item analysis, item to domain analyses, and item to total assessment analyses. 39,40 For the item analysis, we first assessed item difficulty. To do this, we divided the number of respondents who correctly answered the item by the total number that responded to that item. Items with a difficulty score below 0.20 ("too difficult") or above 0.90 ("too easy") were eliminated. 39,40 The item analysis for the BOC Certification Examination uses item difficulty cutoffs between 0.30 and 0.92 , while allowing for accepting items outside those parameters. ${ }^{38}$ We used standard cutoffs to account for the flexibility described by the BOC item analysis approach. ${ }^{38-40}$ Next, we assessed item discrimination which established a point-biserial correlation between item performance and total domain score performance. Items with a correlation below 0.20 were eliminated. 39,40 Item discrimination is an index of an item's effectiveness at discriminating between those who know the content, 
in relation to the overall domain score, and those who do not. ${ }^{39-41}$ The item analysis for the BOC Certification Examination uses a positive value above 0.15 for item discrimination, which is lower than the recommended standard. ${ }^{39-41}$

We also calculated item-total statistics that included corrected item-total correlations, squared and multiple correlations, and an " $a$ if item deleted" analyses. These item-total statistics were considered in combination to make decisions about item elimination. Corrected item-total correlation is a correlation between an item and the rest of the assessment without that item considered part of the examination. ${ }^{39}$ This correlation is intended to identify items that did not measure the same construct that the rest of the examination was trying to measure. ${ }^{39}$ Squared multiple correlation was used to measure how much variability in the responses to one item can be predicted from other items on the assessment. ${ }^{39}$ To determine "a if item deleted" analyzes, the overall instrument reliability coefficient (internal consistency) of the item was deleted. ${ }^{39}$ Items should be considered for elimination when the a value of the item deleted is higher than the current a statistic. ${ }^{39}$

We determined assessment stability between administrations for the remaining items using intraclass correlation coefficients (mixed model, consistency model with averaged measures) for each item and eliminated any items with an ICC less than $0.50 .{ }^{41}$ We then calculated ICC values for the remaining items to determine stability within the domain scores and the entire instrument (total score). Lastly, we calculated a reliability coefficient to establish internal consistency for the entire examination based on the remaining items. The acceptable range for Cronbach's $a$ is greater than 0.60 .41 All statistical analyses were performed using SPSS (IBM SPSS Statistics for Windows, Version 23.0. Armonk, NY: IBM Corp). Significance, where appropriate, was set at p $<0.05$ a-priori.

\section{RESULTS}

In determining item difficulty, we eliminated 42 items from the assessment because they scored below 0.20 or above 0.90 and were deemed "too difficult" ( 20 items) or "too easy" (22 items), respectively. One hundred and seventy-eight items remained and were used for the item discrimination analysis. In the item discrimination analysis, we eliminated 50 additional items because of point-biserial correlations below 0.20 . The item-total statistical analysis affirmed inclusion of all remaining 128 items considering corrected-item total correlations, squared multiple correlations, and " $a$ if item deleted" simultaneously.

Intraclass correlation coefficients analysis revealed weaknesses in an additional 57 items (ICC $<0.5)$, which were then eliminated. The remaining items $(n=71)$ demonstrated good or excellent reliability. The domains demonstrated good or excellent relationships between administrations: Injury/lllness and Wellness Protection ( 8 items, ICC=0.617), Clinical Evaluation and Diagnosis (21 items, ICC=0.807), Immediate and Emergency Care (12 items, ICC=0.712), Treatment and Rehabilitation ( 10 items, ICC=0.770), and Organizational and Professional Health and Wellbeing $(20$ items, ICC $=0.820)$. With the remaining 71 items, the knowledge assessment demonstrated high internal consistency (Cronbach's $a=0.843$ ). A summary of analysis by domain is included in Table 2.

Table 2. Summary of Analysis

\begin{tabular}{|c|c|c|c|c|c|c|}
\hline & Domain 1 & Domain 2 & Domain 3 & Domain 4 & Domain 5 & Total \\
\hline Initial Items & 49 & 63 & 29 & 29 & 50 & 220 \\
\hline $\begin{array}{l}\text { Removed Too } \\
\text { Easy }\end{array}$ & 9 & 5 & 7 & 0 & 1 & 22 \\
\hline $\begin{array}{l}\text { Removed Too } \\
\text { Difficult }\end{array}$ & 8 & 6 & 3 & 1 & 2 & 20 \\
\hline $\begin{array}{l}\text { Removed Poor } \\
\text { Correlation }\end{array}$ & 12 & 12 & 4 & 6 & 16 & 50 \\
\hline Removed ICC & 12 & 19 & 3 & 12 & 11 & 57 \\
\hline Total Removed & 41 & 42 & 17 & 19 & 30 & 149 \\
\hline Remaining & 8 & 21 & 12 & 10 & 20 & 71 \\
\hline
\end{tabular}

\section{DISCUSSION}

We used content experts with experience and training in developing multiple-choice items; these were individuals who have developed items using resources endorsed by the BOC and NATA. We then field tested our items and conducted a thorough a rigorous psychometric analysis. The final pool of items was representative, but not distributed similarly to the BOC Certification Examination, of the practice domains and included both knowledge retrieval and knowledge utilization items that would challenge the clinical reasoning of the AT. ${ }^{20}$ Our result is a pool of questions that can be used to test our larger hypothesis, an alternative model for maintaining competence, beyond the simple act of accumulating CE units. 
Our process of using experts and an educational guide for developing this instrument is consistent with similar approaches for developing assessments for single constructs and larger exams with multiple constructs $42-45$ The American Board of Emergency Medicine uses The Model for the Clinical Practice Emergency Medicine as a guide for item development. ${ }^{46}$ A Taskforce similar to that used to develop the educational competencies oversees that process. ${ }^{46}$ When identifying experts, we looked to those who had been part of developing the competencies to serve as experts. In using both the educational competencies and the Role Delineation Study/Practice Analysis (translated using the Crosswalk Analysis) to guide tool development, we were aligning with the premise shared by the BOC, that for tasks to become entry-level they must first be incorporated into education programs. $19,20,35$ This is also consistent with the BOC's definition, that CE should not only provide for maintaining competence, but also elevating knowledge to current best practice. ${ }^{1}$ When developing the Fresno, Modified Fresno, and Berlin Questionnaire for measuring competence in evidence-based practice for physicians and physical therapists, the authors developed the items themselves using current literature to drive content. ${ }^{42-44}$ We instructed item writers in our study to use both the BOC Exam References and NATA Position Statements to guide item development in their specified area.

Our process for item analysis is also consistent with current practices of the BOC Certification Examination, ${ }^{38}$ the American Board of Emergency Medicine Continuous Certification Examination, 45 and the Maintenance of Certification for Family Physicians Examination. ${ }^{38,45,47}$ These organizations typically field test items and then assess for item discrimination and item difficulty. ${ }^{38,45,47}$ Our analyses went further to look at how the instrument would respond if the item was deleted, both for variability, predictability, and internal consistency. ${ }^{39}$ We also assessed for test-retest reliability, which is not often accomplished in these tests because testing occurs in real-time with professional consequences for test takers. ${ }^{41}$

Continuing education is the acquisition of knowledge or the engagement in learning activities aimed at maintaining or developing knowledge, skills, and abilities resulting in high quality patient care. ${ }^{48} \mathrm{It}$ is suggested that to be effective, CE must be self-directed and must address learner needs. ${ }^{49}$ Our theoretical framework challenges that assumption, particularly if learner needs are drawn only from self-perception, just as we challenge the assumption that simply attending CE sessions leads to continued competence. A similar process is being used by the family medicine and emergency medicine specialties in the medical profession. ${ }^{29-32}$ These professions utilize standards across four tenets, one of which is cognitive expertise, that includes a test to recertify physicians, while we are suggesting the test be used to drive future learning opportunities. As adults, we ascribe to adult learning principles in the pursuit of lifelong learning, but CE is a mandatory process and therefore challenges the idea that $\mathrm{CE}$ is self-directed. Moreover, there is a substantial body of knowledge that describes the preferences, perceived needs, deterrents, and barriers, which is countered by other literature that clearly refutes the relationship between perceived needs and actual cognitive knowledge. ${ }^{4-14,48,50}$ As such, self-directed $\mathrm{CE}$, driven by preference or perceived knowing likely fails to meet the need of the patient.

By using a comprehensive knowledge assessment to measure knowledge needs, athletic trainers may change their beliefs and attitudes about what they know. Instead of considering what they think they know or need, they would have objective data to plan $\mathrm{CE}$. The change in what they know about their own knowledge would likely change their intentions and subsequent behaviors relating to $\mathrm{CE}$ activities. ${ }^{5}$ This is the theory of planned behavior that suggests attitudes and norms shape intentions and eventual action. ${ }^{51} \mathrm{~A}$ standard process with data to drive intention and action are exactly what is needed to reshape the current environment that allows the simple acquisition of credit to meet the expectation for $\mathrm{CE}$.

\section{Limitations}

We aimed to develop a large pool of items for a comprehensive knowledge assessment to measure the actual knowledge of athletic trainers. Although there is a committee of item writers used by the BOC, this information was unattainable, which led to our use of those that developed the educational competencies. Their qualifications were vetted and they were instructed to use content consistent with developing the BOC Certification Examination, but verifying their item writing capacity occurred through the psychometric analysis, not prior to the validation process.

The final pool of items is not equally distributed of items guided by the Role Delineation Study/Practice Analysis and BOC Certification Examination. This suggests more items may need to be developed or refined for inclusion in a future iteration of the assessment. Further, AT performance on the assessment of knowledge was low, even after item difficulty analyses were performed. Although that is consistent with the previous research in athletic training, where actual knowledge has been low, regardless of the content area, retesting among high performers or validated group of test takers may serve to better inform us about the validity of the tool. . $^{4}$ Identification of this group of test takers may be difficult, but in other professions and with smaller constructs, educators and students have been used for this kind of comparative analysis. ${ }^{33-35}$ Questions similar to those represented in Figure 1, were eliminated as too difficult. It is possible, that with improved overall performance, more items would have remained within the final pool of items. 
Individuals with the following medical condition are 37 times more likely to die than those without the condition during sport

a. Hypertrophic cardiomyopathy $(131,68.6 \%)$

b. Sickle cell trait $(34,17.8 \%)$

c. Wolf parkinson's white syndrome $(16,8.4 \%)$

d. Anomalous coronary arteries $(7,3.6 \%)$

Missing responses $(3,1.6 \%)$

What is the usual, randomly taken, blood sugar level of a person?
a. $\quad 67 \mathrm{mg} / \mathrm{dl}(28,14.7 \%)$
b. $\quad 102 \mathrm{mg} / \mathrm{dl}(114,59.7 \%)$
c. $126 \mathrm{mg} / \mathrm{dl}(43,22.5 \%)$
d. $185 \mathrm{mg} / \mathrm{dl}(4,2.1 \%)$

Missing responses $(2,1.0 \%)$

Provided there is the appropriate number of clinicians to assist, which is the best evidence-based method of spine-boarding for an athlete that is prone?
a. $8+\operatorname{lift}(79,41.4 \%)$
b. Log roll $(62,32.5 \%)$
c. Prone log roll push $(15,7.8 \%)$
d. Prone log roll pull $(33,17.3 \%)$

Missing responses $(2,1.0 \%)$

The proportion of people with a positive diagnostic test who do actually have the disease (or injury)
a. Positive predictive value $(37,19.4 \%)$
b. Positive probability $(9,4.7 \%)$
c. True positive $(135,70.7 \%)$
d. Prevalence $(6,3.1 \%)$
Missing responses $(4,2.1 \%)$

Figure 1. Items Deemed Too Difficult During the Item Difficulty Analysis

\section{CONCLUSIONS}

Medical specialties have determined that neither recertification nor singularly self-directed approaches to maintaining competence have been effective at mitigating errors in patient care. As such, a multi-faceted approach that includes an assessment of cognitive competence has been used. Although we are not suggesting we use a knowledge assessment as a means to recertify, we do believe the process is consistent with the move toward the practice improvement processes currently being integrated into medical specialties. Our current processes in athletic training are neither measuring nor ensuring maintenance of competence. We have developed a valid and reliable pool of items and entire tool that represent the domains of athletic training practice. Future research should focus on developing and validating additional items so that the test can be consistent with the BOC Certification distribution of items by domain. In the big picture, we should also consider incorporating a comprehensive knowledge assessment, in conjunction with other measures of professionalism and competence to better maintain competence in athletic trainers. In the meantime, to influence $\mathrm{CE}$ planning behavior, we should use a knowledge assessment to more objectively guide CE activities.

\section{REFERENCES}

1. Board of Certification. Continuing Education. Available at: http://www.bocatc.org/athletic-trainers\#maintaincertification. Accessed on April 16, 2017.

2. Davis D. Does CME work? An analysis of the effect of educational activities on physician performance or health care outcomes. Int Journal of Psychiat Med. 1998;28(1):21-39.

3. Board of Certification. What is the BOC? Available at: http://www.bocatc.org/about-us\#what-is-the-boc. Accessed on November 17, 2018.

4. Hughes $B$. Identifying attitudes and deterring factors toward continuing education among certified athletic trainers. Internet J Allied Health Sci Pract. 2005;3(1).

5. Eberman LE, Tripp BL. Effect of performance feedback in perceived knowledge and the likelihood to pursue continuing education. Athl Train Educ J. 2011;6(2):69-75.

6. Edler JR, Eberman LE, Kahanov L, Roman C, Mata H. Knowledge of Athletic Trainers Regarding Airway Adjuncts. Athl Train Educ J. 2015;10(2):164-169.

7. Edwards SD, Eberman LE, Peterson RC, Games KE. Certified athletic trainers' knowledge of posterolateral corner injuries. J Athl Train. 2015:50(6 Supplement);S-203. 
8. Neil ER, Games KE, Kahanov L, Eberman LE. Knowledge of athletic trainers and emergency personnel regarding management of the spine injured athlete. Athl Train Educ J. (In Press).

9. Baxley SG, Brown ST, Pokorny ME, Swanson MS. Perceived competence and actual level of knowledge of diabetes mellitus among nurses. J Nurses Staff Dev. 1997;13(2):93-98.

10. Chan MF, Zang YL. Nurses' perceived and actual level of diabetes mellitus knowledge: results of a cluster analysis. $J$ Clin Nurs. 2007;16(7B):234-242.

11. Drass JA, Muir-Nash J, Boykin PC, Turek JM, Baker KL. Perceived and actual level of knowledge of diabetes mellitus among nurses. Diabetes Care. 1989;12(5):351-356.

12. el-Deirawi KM, Zuraikat N. Registered nurses' actual and perceived knowledge of diabetes mellitus. J Nurs Staff Dev. 2001;17(1):5-11.

13. Lehna $\mathrm{C}$, Myers J. Does nurses' perceived burn prevention knowledge and ability to teach burn prevention correlate with their actual burn prevention knowledge? J Burn Care Res. 2010;31(1):111-120.

14. Naughton CA, Friesner DL. Comparison of pharmacy students' perceived and actual knowledge using the Pharmacy Curricular Outcomes Assessment. Am J Pharm Educ. 2012;76(4):63.

15. Walters Report to USM Board of Regents. An independent evaluation of the procedures and protocols related to the June 2018 death of a University of Maryland Football Student-Athlete. Available at: http://apps.washingtonpost.com/g/documents/sports/investigation-in-death-of-maryland-football-player-jordanmcnair/3214/. Accessed on: November 17, 2018.

16. Plancher vs. UCF Athletics Association , Inc., et al. (Supreme Court of Florida: Case No. SC13-1872 and SC13-1874.)

17. Cook TM, Woodall N, Frerk C. Major complications of airway management in the UK: results of the Fourth National Audit Project of the Royal College of Anaesthetists and the Difficult Airway Society. Part 1: anaesthesia. British Journal of Anaesthesia. 2011; 106: 617-31.

18. Cook TM, Scott S, Mihai R. Litigation related to airway and respiratory complications of anaesthesia: an analysis of claims against the NHS in England 1995-2007. Anaesthesia. 2010; 65: 556-63.

19. National Athletic Trainers' Association. Athletic Training Educational Competencies (5th ed). Available at: https://www.nata.org/sites/default/files/competencies_5th_edition.pdf. Accessed on April 16, 2017.

20. Board of Certification. Role Delineation Study/Practice Analysis ( $6^{\text {th }}$ ed). 2011. Omaha, NE.

21. Nilsson G, Hjemdahl P, Hässler A, Vitols S, Wallen N, Krakau I. Feedback on prescribing rate combined with problemoriented pharmacotherapy education as a model to improve prescribing behaviour among general practitioners. Eur $J$ Clin Pharm. 2001;56(11):843-848.

22. Doyne EO, Alfaro MP, Siegel RM, et al. A randomized controlled trial to change antibiotic prescribing patterns in a community. Arch Pediat Adol Med. 2004;158(6):577.

23. van Eijk ME, Avorn J, Porsius AJ, de Boer A. Reducing prescribing of highly anticholinergic antidepressants for elderly people: randomised trial of group versus individual academic detailing. Brit Med J. 2001;322(7287):654.

24. Clark NM, Gong M, Schork MA, et al. Impact of education for physicians on patient outcomes. Pediatrics. 1998;101(5):831-836.

25. Veninga $C C, P L \varnothing v$, Wahlström $R$, et al. Evaluating an educational intervention to improve the treatment of asthma in four European countries. Am J Resp Crit Care. 1999;160(4):1254-1262.

26. Fender GR, Prentice A, Gorst T, et al. Randomised controlled trial of educational package on management of menorrhagia in primary care: the Anglia menorrhagia education study. Brit Med J. 1999;318(7193):1246-1250.

27. Dolan NC, Ng JS, Martin GJ, Robinson JK, Rademaker AW. Effectiveness of a skin cancer control educational intervention for internal medicine housestaff and attending physicians. J Gen Intern Med. 1997;12(9):531-536.

28. Gerstein H, Reddy S, Dawson K, Yale J, Shannon S, Norman G. A controlled evaluation of a national continuing medical education programme designed to improve family physicians' implementation of diabetes-specific clinical practice guidelines. Diabetic Med. 1999;16(11):964-969.

29. Marco CA, Counselman FL, Korte RC, Russ CM, Whitley CT, Reisdorff EJ. Emergency physicians maintain performance on the American Board of Emergency Medicine Continuous Certification (ConCert) Examination. Acad Emerg Med. 2014;21:532-537.

30. O'Neill TR, Puffer JC. Maintenance of certification and its association with the clinical knowledge of family physicians. Acad Med. 2013;88:780-787.

31. Peterson LE, Blackburn B, Peabody MR, O'Neill TR. Family physicians' scope of practice and American Board of Family medicine recertification examination performance. J Am Board Fam Med. 2015;28:265-270.

32. Peabody MR, O'Meill TR, Puffer JC. Performance on the maintenance of certification for family physicians (MC-FP) examination: comparisons of initial certifiers with experienced physicians. J Am Board Fam Med. 2015;28(2):294-295.

33. Hooker RS, Carter R, Cawley JF. The national commission on certification of physician assistants: history and role. J Physician Assist Educ. 2004; 15(1), 8-15. 
34. Jones JH, Smith-Coggins R, Meredith JM, Korte RC, Reisdorff EJ, Russ CM. Lifelong learning and self-assessment is relevant to emergency physicians. J Emerg Med. 2013;45(6):935-941.

35. Board of Certification and Commission on Accreditation of Athletic Training Education. Crosswalk Analysis: Role Delineation Study/Practice Analysis $6^{\text {th }}$ ed. vs. Athletic Training Education Competencies, $5^{\text {th }}$ ed. Available at: http://www.bocatc.org/system/document versions/versions/47/original/boc-nata-crosswalk-analysis20170615.pdf?1497544976. Accessed on April 16, 2017.

36. Board of Certification. Exam References. Available at: http://www.bocatc.org/candidates\#exam-preparation-tools. Accessed on November 17, 2018.

37. National Athletic Trainers' Association. NATA Position Statements. Available at: https://www.nata.org/newspublications/pressroom/statements/position. Accessed on November 17, 2018.

38. Board of Certification. Item Analysis Explanation. Available at: http://www.bocatc.org/system/document versions/versions/1/original/castle-item-analysis-explanation20170523.pdf?1495566366. Accessed on April 16, 2017.

39. The University of Texas at Austin Faculty Innovation Center. Item Analysis. https://facultyinnovate.utexas.edu/sites/default/files/iar-assesslearning-exams-item_analysis.pdf. Accessed May 24, 2017.

40. Pennsylvania State University. Schreyer Institute of Self-Paced Modules. Item Analysis. Available at: http://sites.psu.edu/itemanalysis/. Accessed November 17, 2018.

41. Portney LG, Watkins MP. Foundations of clinical research: applications to practice. 2008. Prentice Hall, Upper Saddle River, NJ.

42. Ramos KD, Schafer S, Tracz SM. Validation of the Fresno Test of Competence In Evidence Based Medicine. BMJ. 2003;326(7384);319-321.

43. Tilson JK. Validation of the modified Fresno Test: assessing physical therapists' evidence based practice knowledge and skills. Br Med Ed. 2010;10:38.

44. Fritsche L, Greenhalgh T, Falck-Ytter Y, Neumayer HH, Kunz R. Do short courses in evidence based medicine improve knowledge and skills? Validation of Berlin Questionnaire and before and after study of courses in evidence based medicine. BMJ. 2002;325(7376):1338-1341.

45. American Board of Emergency Medicine. EM Model. Available at: https://www.abem.org/public/publications/emmodel/reference. Accessed on April 16, 2017.

46. Counselman FL, Babu K, Edens MA, Gorgas DL, Hobgood C, Marco CA, Katz E, Rodgers K, Stallings LA, Wadman MC, for the 2016 EM Model Review Task Force; Beeson MS, Keehbauch JN, for the American Board of Emergency Medicine. The 2016 model of the clinical practice of emergency medicine. J Emerg Med. 2017;pii: S07364679(17)30108-7.

47. O'Neill T, Peabody M, Blackburn B, Peterson L. Creating the Individual Scope of Practice (I-SOP) Scale. J Appl Meas. 2014;15(3):227-239.

48. Armstrong KJ, Weidner TG. Preferences for and barriers to formal and informal athletic training continuing education activities. J Athl Train. 2011;46(6):680-687.

49. Davis NL, Willis CE. A new metric for continuing medical education credit. J Cont Educ Health Prof. 2004;24(3):139144.

50. Cuppett MM. Self-perceived continuing education needs of certified athletic trainers. J Athl Train. 2001;36(4):388-395.

51. Ajzen, I. From intentions to actions: A theory of planned behavior. In Action control (pp. 11-39). 1985. Springer, Berlin, Heidelberg. 